\title{
Lo oculto y lo manifiesto: apuntes para una poética del lenguaje musical
}

Entrevista al compositor Jorge Ritter

¿Podría decirnos, Maestro, de qué manera están relacionados los aspectos formales de la composición musical y sus efectos estéticos?

Antes que nada, habría que distinguir entre el efecto estético que surge espontáneamente, y que es imprevisible por parte del compositor, y el efecto estético calculado, producto de ciertas fórmulas técnicas.

La música tiene una peculiaridad en relación con otras artes. En relación con la literatura, por ejemplo, la música no tiene un contenido descifrable. Aunque también las letras pueden ser ambiguas, crean la ilusión de tener un sentido; la música, en cambio, nunca pretende tener un fondo o un contenido que pueda glosarse en términos ajenos a ella. Tiene una cualidad abstracta en cuanto al sentido. Y por esta cualidad abstracta, "no dice nada" exterior a la historia misma que está desplegando. De modo que podríamos decir que, en vez de representarlos, "sobrevuela" los significados.

Un músico, por más bueno que sea, no puede significar de un modo literal la idea de "matar, "comer", "manzana", "vino", "tristeza”... No se puede. La música depende de sí misma para 
crear significado. Su forma es su fondo. Y en este sentido, el primer sonido que oigo como compositor va a ser génesis de todo un compendio de significados.

Si yo comienzo con un tenue sonido de flauta, y después de unos instantes hago que toda la orquesta suene en fortissimo, voy a crear, a partir de esa primera proposición, todo un código de signos, pero internos. Voy a crear, para empezar, una sensación de contraste. Voy a hacer sentir el peso de lo que es "fuerte", en relación con lo que yo había insinuado como débil o delicado al principio.

Así pues, la música implica la instauración de todo un vocabulario en cada obra. Pero, paradójicamente, se puede decir que hay pocas artes que estén tan impregnadas de clichés, o de "lugares comunes", como la música. Es difícil encontrar otro arte que represente tan fielmente una época, por ejemplo. Cuando escuchamos a Mozart, no es sólo el espíritu del rococó o del clasicismo lo que escuchamos; entramos en contacto con toda una serie de giros melódicos, lugares comunes y manierismos que son característicos de su época. Pero claro, lo que hace maravillosas las composiciones de un Mozart o un Haydn, es el hecho de que en medio de tantas fórmulas previsibles surge algo original, indefinible. Ese "algo" sobrevuela encima de los códigos y principios, creando una intensa expresividad.

Como la música depende tanto de sus "citas de sí misma", el compositor corre siempre el riesgo de no crear sino un gran cliché. Con este problema se enfrenta cada vez que se propone componer en un estilo determinado, como el rock o el jazz, siguiendo fórmulas consabidas y recurriendo a tal o cual atmósfera precodificada.

Lo más interesante es atender al efecto que puede tener la música como algo no calculado, y ello se relaciona básicamente con el aspecto emocional, que es la sustancia misma de este arte. La música cultiva ante todo una serie de estados emocionales. 
Bernstein habla, por ejemplo, del efecto emocional que genera la alternancia entre consonancia y disonancia, o bien la dialéctica entre sonido y silencio.

Más allá de una definición mental o intelectual, dicha alternancia crea una impresión directa en las emociones.

El músico está siempre jugando, pues, con un código emocional. Sin embargo, es un hecho que la cultura occidental no es muy avezada en el lenguaje de las emociones. Como decía Khrisnamurti, el filósofo hindú, nuestra cultura "ha llenado el corazón con las cosas de la mente". Y esto se refleja en la enseñanza, disección y análisis de las artes. Todas estas actividades hablan al intelecto, glosan el catálogo de ideas, de preceptos que se actualizan en una expresión artística determinada. Inclusive esto que he mencionado sobre la alternancia de consonancias y disonancias es una idea que básicamente se dirige a nuestra mente.

Pero el músico se enfrenta en lo concreto al efecto de esta alternancia. Y se da cuenta, por ejemplo, de que la disonancia genera una tensión, un malestar, y de que al convertirla en consonancia, esa tensión se alivia. En ese juego entre tensión y alivio despierta el corazón, el centro emocional de quien escucha.

Es cierto que puede haber una manera muy calculada de crear un efecto estético mediante técnicas musicales. Así por ejemplo, pueden usarse ciertos elementos de grandilocuencia orquestal, o acordes básicos cuyas asociaciones interpelan al inconsciente colectivo para garantizar uno $\mathrm{u}$ otro resultado. Pero, sin duda, ello entraña otros peligros.

Ya Schöenberg, compositor expresionista vienés que introdujo el sistema serial, hablaba de la necesidad de hacer una música que no fuese considerada "bella". Quería replantear nuestra noción de "lo estético". Siguiendo las teorías de un Nietszche o un Freud, consideraba más importante que cualquier canon de belleza, el hecho de que la música expresara con honestidad la sustancia oscura del inconsciente individual 
del artista. Es preferible reflejar eso, decía, que reflejar una estética heredada — como la del siglo XVIII-, con sus ideales de equilibrio, de simetría, de supremacía de la razón, donde por encima de la estética está la ética, como en el caso de Schiller o Beethoven: en la Novena sinfonía escuchamos, por encima de la forma musical, los versos exaltados del "Himno a la alegría", que tienen un evidente contenido moral, una intención edificante.

Aquella idea de Kierkeegard de que los ideales éticos deben predominar sobre lo estético no convencía ya a un Schöenberg, para quien era más "ético" expresar la fealdad, la imperfección humana, así como los sufrimientos y angustias de su siglo —un siglo de guerras, maquinismo, vuelos de la imaginación, y holocausto. Preferible expresar esta confusión, esta oscuridad de la civilización, o incluso la nueva tendencia a lo matemático o a lo exacerbadamente racional del nuevo siglo, que seguir constreñidos a la estética idealista de la belleza.

Ahora que menciona cómo las nuevas tendencias estéticas del siglo veinte adoptan nociones provenientes del pensamiento matemático, tecnológico e incluso psicoanalítico, ¿podría usted ahondar en la relación de la música con otros lenguajes científicos, técnicos y artísticos?

Hay que considerar que la música es la actividad artística que mejor se presta para hacer analogías. Al componer música puedes expresar un pensamiento de carácter arquitectónico. O puedes responder a una lógica puramente matemática. Así, por ejemplo, puedes basarte en una analogía como "la proporción áurea" de los antiguos. El compositor asigna a cada sonido unos valores correspondientes a la proporción áurea, y puede, a partir de ahí generar toda una pieza regida por ese principio estructural. 
Pero también podría ocurrírseme componer con base en el lenguaje Morse. Escogería una serie de nombres, el tuyo, el mío. Y luego le asignaría a cada una de la señales cortas y largas de ese código, un patrón rítmico que estructuraría la obra entera. Claro que el público nunca se enteraría de que, tras las estructuras musicales, estarían cifrados nuestros nombres. Se trata en este caso de un proceso precomposicional que sirve para estructurar, pero en realidad poco tiene que ver con lo que la música transmite.

Hasta fines del siglo XIX, como decía antes, la música no se había desligado de un código emocional. Si se analizan las fugas de Bach, es claro que por encima de su estructuración matemática, esa perfección casi científica de sus composiciones, está la expresión, la armonía, este pathos estrictamente emocional que predomina. Y es que Bach sabía muy bien como "traicionar" el propio código que usaba, con una nota discordante, por ejemplo. Y esa discordancia hacía las veces de una respuesta a otro nivel. En este sentido, podemos decir que tal "imperfección" respecto de la estructura formal es lo que en verdad "significa".

Es lo mismo que sucede en la figura humana con la presencia del ombligo. El ombligo no tiene ya ninguna función y parece un defecto inútil en el cuerpo de un individuo; pero considerando al ser humano como especie, el ombligo representa la conexión entre las generaciones. En la música hay muchos niveles de percepción. Lo que en un nivel aparentemente rompe con el esquema, con la perfección formal de su estructura, en realidad provoca un paso a otro nivel, donde esa imperfección adquiere mucho sentido.

Esto ocurre también con la relación armónica y la relación melódica entre los sonidos. A nivel melódico hay notas que están muy lejos unas de otras, considerando la secuencia lineal de una escala, como es el caso de una quinta (i.e. de do a sol) o de una octava (de un do medio a un do alto); en términos me- 
lódicos se trata de brinco muy largo, y sin embargo, a nivel del universo armónico, constituido por relaciones de "simpatía" acústica entre las notas - es decir, proporciones entre la cantidad de vibraciones por segundo- - la octava y la quinta son en realidad los intervalos más cercanos en términos de percepción y de realidad física.

Hay, pues, en la música, muchos niveles de percepción de los que no podría hablarse si se analizan sólo sus estructuras formales codificadas, su gramática estricta, que en la mayoría de los casos resulta además extremadamente simple y previsible.

En cuanto a este pathos del que usted habla en relación con el contenido emocional de la música, ¿cuál es la relación de las formas musicales con la naturaleza, con el cuerpo, o con las características fisiológicas de la percepción?

De hecho, sí se da una relación más o menos directa. Hay una vieja idea que sostiene que el hombre no es uno sino tres: es mente, es corazón y es cuerpo. Se podría decir que el hombre tiene esos tres aspectos fundamentales, casi casi como si se tratara de tres cerebros. Cada uno opera a distinta velocidad y por distintas vías, sobre los estímulos sensoriales. Tenemos, pues, reacciones instintivas, físicas, que son instantáneas. Tenemos reacciones emocionales más complejas, que son también muy veloces. Y tenemos reacciones intelectuales, que implican un procesamiento más lento y complicado.

Dado que la música tiene una gran capacidad de analogía con cualquier fenómeno de la realidad, su conformación da cuenta también de nuestra naturaleza humana. Es un hecho que nuestras facultades instintivas, emocionales e intelectuales actúan simultáneamente. De manera análoga, la música, que se basa en la simultaneidad, interpela estos tres niveles de la percepción humana. 
Así por ejemplo, cada uno de los acordes a partir de los cuales se conforma gran parte de la música popular, e incluso "culta", pone en convivencia tres notas completamente distintas y de distintas velocidades: una nota fundamental, cuyas vibraciones son más lentas que las de sus armónicos (el armónico de octava, de quinta, de cuarta, de tercera, etc.), y otras dos que surgen precisamente de tales armónicos.

Hay otro aspecto musical que se relaciona directamente, y por analogía, con el cuerpo. Se trata del aspecto rítmico. La intermitencia y frecuencia en que un sonido aparece y desaparece alude a los ritmos fisiológicos: como el latido del corazón, la alternancia respiratoria, y otros pulsos que de continuo dan vida a nuestro organismo. El ritmo habla al cuerpo.

Una de las manifestaciones más evidentes de esta apelación directa al cuerpo es la música africana, cuyo rescate e influencia ha sido crucial en toda la música del siglo xx. Frente a toda una tradición europea de los grandes compositores, se afirma la presencia de la música negra en toda la cultura contemporánea: desde el ragtime, el chárleston, el jazz, hasta el rock de los sesenta y otras tendencias asociadas con movimientos de liberación de la sexualidad.

La música africana está totalmente basada en el ritmo, y por eso es sensual y antisolemne. Tiende, pues, a detener este "pathos emocional" que generaba la música culta europea. Frente a dicha tradición, el despliegue del aspecto rítmico tiene en nuestros oídos modernos un efecto no sólo anestesiante sino francamente curativo.

Si pensamos en una música como la de Wagner, con su atmósfera no sólo exacerbadamente emocional y "patética" sino casi patológica — de hospital psiquiátrico, diríamos—, donde se da una hipertrofia, una exponenciación de lo emocional, entendemos por qué en nuestro siglo surge este gusto por la música africana, rítmica, instintiva y casi meditativa que contrasta con el padecimiento romántico y expresionista. 
Sin embargo, sobre todo durante las últimas décadas, ha habido también una exacerbación de lo rítmico hasta llegar a una mecanización monótona y casi autista, que se ha convertido asimismo en fórmula de la composición musical. Esta fórmula actúa como una droga, sobre todo para una audiencia joven. Baste pensar en la música electrónica donde prevalecen los "loops" rítmicos generados por una máquina, patrones reiterativos en los que se insertan formas armónicas y melódicas muy elementales; o en los estilos del rock o de la llamada "música pop", donde la poderosa base rítmica y su energía orgánica modela y condiciona toda la expresividad.

Es un hecho que el aspecto rítmico se había apenas desarrollado antes del siglo XIX ${ }^{1}$. Ciertamente encontramos en Mozart o Beethoven un tratamiento rítmico al lado del complejo tratamiento melódico o armónico; pero en ellos, lo mismo que en Mendelssohn o Wagner, la estructura rítmica es más bien simple. Nunca como ahora había prevalecido el ritmo por sobre otros niveles de la música.

Mientras que los contenidos emocionales parecen expresarse mejor mediante fórmulas armónicas y melódicas, los aspectos físicos, corporales, sensuales se expresan mejor mediante recursos rítmicos.

En cuanto a la conceptualización y estudio de la música como un lenguaje, ¿se puede estudiar la música como un discurso lineal?; ¿o cuál sería la mejor estrategia para analizar y comprender la música sin traicionar ni desvirtuar su naturaleza?

Cuando se quiere penetrar analíticamente la música se tiende a disecar el fenómeno. El análisis se vuelve a menudo muy

\footnotetext{
${ }^{1} \mathrm{Si}$ bien en la Edad Media había procedimientos rítmicos complejos (piénsese en el Ars Nova, por ejemplo), a partir del barroco se abandonará esta búsqueda en favor del desarrollo del aspecto melódico-armónico.
} 
abstracto, arbitrario y pocas veces da cuenta de su carácter artístico, es decir, de su poética particular.

Una de las primeras cosas que saltan a la vista a la hora de hacer un análisis musical es la enorme cantidad de aspectos que pueden estudiarse. Podría hacerse todo un mapa de la textura musical de una pieza, por ejemplo cuando hablo de "textura" me refiero a la presencia y alternancia de instrumentos y timbres que habrán de participar en la interpretación.

También puede analizarse la melodía en sus múltiples aspectos: Si está basada en lo vocal, asociada con un texto, adquiere la dinámica específica de la voz humana. La melodía que tiene esa particular "vocación" se caracterizará por mostrar secuencias de notas contiguas, y se moverá con mínimas alteraciones, lo que la asimila al habla. Muchos de los géneros musicales antiguos se definían por analogía con las formas literarias de la época, a veces simplemente porque las melodías se componían como soporte de versos, salmos, rezos, etc. Pero también es posible que la melodía de la pieza que estemos analizando transcurra de acuerdo a las dinámicas de un instrumento y dependa de su índole peculiar, física y sonora. Así por ejemplo, podemos tener una melodía que siga las dinámicas de un corno, con notas largas; puede tratarse de una melodía simple o compleja, pero ha de responder en todo momento a las posibilidades del instrumento en cuestión y a las secuencias y atmósferas que éste es capaz de generar. Como compositor, te ves en la necesidad de cuidar que tus melodías evoquen realmente la naturaleza íntima del instrumento musical que habrá de interpretarlas.

A mis alumnos les hablo de la conveniencia de establecer, en cada ocasión, los parámetros que puedan ser más adecuados para analizar una determinada obra musical. Muchas veces lo que hay que hacer es inventar esos parámetros, en vez de recurrir a los que habitualmente se manejan en la enseñanza tradicional de la música. Es posible que para analizar una pie- 
za del siglo XIX, yo les proponga hacerlo a partir de sus "frases", de la sintaxis que se establece entre estas "frases melódicas", que funcionarán en nuestro análisis como unidades o signos complejos que se combinan de cierto modo. Se tratará entonces de un análisis fraseológico que implicará conocer la retórica propia de una época, para poder determinar cómo esta retórica se cumple o se "traiciona" con miras a obtener nuevos efectos expresivos.

Pero puedo también proponer otro parámetro de estudio, un parámetro físico, por ejemplo, que, distinguiendo entre notas altas (de frecuencias rápidas) y notas bajas, nos permita dibujar el esquema de clímax y distensiones que se dan a lo largo de una composición.

Hay otra forma de analizar la composición, y ésta sería a partir de las intenciones y estrategias utilizados por el compositor.

Hace poco leí un artículo del compositor mexicano Julio Estrada, siempre crítico y original respecto de sus contemporáneos, cuya tesis es que la enseñanza actual de la música es inadecuada: más allá de estudiar las estructuras musicales en abstracto, habría que hacer una análisis profundo de las intenciones expresivas de los autores, así como de los recursos de que echan mano. Los alumnos de composición tendrían a su vez que analizar sus propias intenciones, lo que implica una especie de introspección - casi psicoanalítica-, y a partir de ahí adoptar las formas más adecuadas para dar curso a dichas intenciones.

Pero si admitimos que en la música no existen contenidos previos... y que la forma musical no es una "ilustración" de intenciones...

En efecto, ése sería el problema que veo en el planteamiento de Estrada. Sin embargo, cabe aclarar que, para él, la com- 
posición musical no sería propiamente una ilustración, en la medida en que no pretende "traducir" una determinada narrativa en discurso musical, ni hacer con la música una mímesis de algún fenómeno natural.

¿...como hizo Debussi con el mar?

En cierto modo... Pero hay que entender la "intención creativa" de otra manera: es probable que la intención del compositor sea simplemente "sonar", convertirse en un "ente sonoro" con ciertas características.

Vale la pena cuestionar aquí la noción que tenemos de música. Las artes en general "se inflaron" mucho durante el siglo XIX, especialmente con el romanticismo y las ideas de Lord Byron, Oscar Wilde, Baudelaire. Se generó entonces una concepción casi religiosa del arte, una idea de que el arte es mucho más de lo que en realidad es; se dijo que el arte era un medio de salvación del alma y del mundo. Se hablaba del artista como un ser iluminado, que expresaba las realidades más recónditas. Posteriormente hubo una fuerte reacción contra este ideal romántico, un tanto ingenuo e infatuado. Un Stravinsky o un Schöenberg plantearon la necesidad de hacer un arte menos idealista y más vital, más rítmico, y por lo mismo, menos "emocional", aunque siguiera buscando ser expresivo. Esto se acentúa durante el siglo xx, y hace explosión en la música popular de los años sesenta.

Sin minimizar el aspecto "redentor" o iluminador de las artes, vale la pena ubicar con más precisión el poder de la expresión estética. Borges dice que la obra de arte tiene el carácter de una revelación inminente, pero una revelación que finalmente no se produce. La idea es interesante. El hecho de que, como en el teatro, la interpretación musical tenga la cualidad de ofrecer una impresión en el presente de quien escucha, y que sea efímera - pues transcurre y muere como una repre- 
sentación teatral, como la vida misma-, aporta este carácter de inminencia al que el poeta se refiere. $Y$ tal "inminencia" de una revelación que no se consuma en quizá lo que llamamos "el hecho estético".

Cuando oigo a Beethoven, o a Bach, siento que se me va a aparecer Dios, o el Diablo - en cierta ocasión, escuchando un Preludio, sentí miedo. Pero tal aparición no llega a consumarse. Esta idea me parece un buen punto de partida para abordar lo estético.

Pero volviendo a lo que decíamos: las artes en el pasado tenían una función, y ahora tienen otra muy distinta. Concuerdo con Estrada en que se nos enseña muy parcialmente lo que ha sido la música. Se nos dice, por ejemplo, que el compositor debe básicamente dominar nociones clásicas, como el contrapunto que se usaba en el siglo XVI — y que ya ni siquiera Bach respetaba-, y debe estructurar sus formas musicales de acuerdo a una estética ya anacrónica. Se nos enseña a componer, por ejemplo, melodías libres que no tengan un leit motiv, que no repitan nunca el mismo motivo, como se hacía en el XVI; siendo que ya en el siglo siguiente, en el XVII, con el barroco, lo que predominó fue "el motivo". De ahí hasta el siglo XIX, las reglas del contrapunto fueron siendo sustituidas por el despliegue de una concepción mayormente centrada en la armonía.

Y hablando del desarrollo de la armonía, cabe aludir a otro aspecto histórico muy importante, casi atávico, que es la preeminencia de la tonalidad como base de la composición, hasta fines del XIX. Tonalidad, como usted sabe, se le llama a todo el sistema de tonalidades mayores y menores que se desprenden de las 12 notas de la escala. Adoptando como base un centro de gravedad, una nota fundamental, las tonalidades mayores y menores que gravitan en torno a ella se alternan y combinan según ciertos parámetros de relaciones para generar todo un universo musical cromático, un sistema autoreferencial completo. 
Pues bien, este lenguaje tonal no cambió a lo largo de casi tres siglos. Incluso Beethoven, quién fue innovador en diversos niveles, retando las formas tradicionales de composición a fin de expresar toda una atmósfera de vigor, grandeza, locura y depresión, se ceñía a un lenguaje tonal y sus requerimientos. El reto que hizo a la tonalidad y la consonancia no fueron sino meras variaciones.

No es sino hasta el siglo xx cuando se da una ruptura con la tonalidad. Eso marcará un cambio absoluto en la aproximación al fenómeno musical.

El uso de la tonalidad como principio de composición constriñe ciertamente al compositor actual a una estética de siglos pasados. Y por eso muchos autores contemporáneos que buscan ser originales, huyen de ella. Y sin embargo, es un hecho que se sigue utilizando porque conlleva importantes beneficios:

En primer lugar, la tonalidad permite al músico el arte de la cita, citar cualquier cosa del pasado, y de este modo aprovechar toda una tradición en sus composiciones, contradiciendo así la ilusión iconoclasta de las vanguardias. De hecho, el artista no siempre puede plantear, como desearía Estrada, la génesis de una nueva música. Puede acaso proponer nuevas visiones de lo que la tradición le ofrece, pero difícilmente nuevos alfabetos con capacidad de un desarrollo ulterior.

En este sentido, el uso de la tonalidad tiene una fuerte ventaja: es fácilmente inteligible para cualquier escucha que tenga una mínima cultura musical. Y por eso la música popular contemporánea sigue echando mano del sistema tonal, e incluso del sistema modal, que recupera sistemas melódicos muy antiguos, medievales y anteriores. Esta recurrencia al lenguaje tonal sin duda acerca las expresiones musicales populares a los hábitos de percepción de cualquier público. Yo sé que si utilizo un cierto acorde, te puedo remitir a Wagner, o los Beatles, al jazz o a la Edad Media. Citar formas musicales del pasado puede significar una gran riqueza para el compositor. 
¿Por qué no podría un estudiante de música en Brooklyn recrear en pleno año 2003 la atmósfera emocional de una pieza sufí del año 1000? Hemos de decir que, en el siglo xx, el arte es en gran parte una cita.

Después del rechazo que hizo el serialismo de la tonalidad, arguyendo que estaba agotada, hubo una recuperación que alcanza a la música "pop", tan extendida en nuestros días, y cuya característica es la incorporación de una serie de híbridos entre formas armónicas antiguas y modernas. En todas estas fusiones, sin embargo, se preserva el principio tonal de gravitar en torno a una nota central, en una escala.

Pero hay también un aspecto negativo en el uso contemporáneo de la tonalidad, y es que restringe en cierto modo la posibilidad de expresar genuinamente algo nuevo.

¿Es eso lo que intentó la música minimalista?

No, por el contrario. El minimalismo adoptó una postura más humilde, menos pretensiosa. Redujo el uso de elementos musicales, ciñéndose al concepto de repetición. Si consideras tú que cada vez que escuchamos un motivo repetido, lo percibimos como algo diferente, podemos asegurar que la reiteración misma crea sentido. La música minimalista repite células, motivos rítmicos o bien melódicos, y así genera una atmósfera peculiar, tal como sucede en la pieza "Drumming" de Steve Reich o en las composiciones de Phillip Glass.

Pero volviendo al tema del abandono de la tonalidad, ¿cuáles han sido las estrategias de la música atonal contemporánea?

La música atonal y los experimentos formales que se dieron en el siglo xx han seguido principios muy diversos, a veces tomados de la arquitectura, de las matemáticas, del lenguaje lite- 
rario e incluso del diseño gráfico. Tenemos así obras musicales que responden a un esquema puramente visual en las partituras.

Entre estos fenómenos musicales podríamos encontrar una pieza que se llamara, por ejemplo, "Densidades", donde el principio rector serían las distintas texturas tímbricas, el juego de densidades entre instrumentos, y donde la intención podría ser algo así como... imitar la presión atmosférica.

Muchas de estas obras tienen un alto grado de perfección formal, y en ese sentido pueden ser consideradas "música". Sin embargo, y pese a ser una expresión genuina del creador, no serían propiamente "música", como diría Bernstein, en la medida en que se apartan por completo de los principios tradicionales que han regido el arte musical, como un arte autónomo en sus formas.

Y en su caso personal, Maestro, ¿cuáles son los principios que usted como compositor prefiere seguir?

Como creador, es preciso pensar mucho para dejar de pensar. Yo no puedo aproximarme a la obra a partir de una conclusión. Mi principio rector no es una elección técnica o racional previa a la música. Mi principio es el lirismo. Sólo así puedo preservar cierta candidez creativa que responda a una necesidad primaria de expresarme.

El impulso de componer se manifiesta en el ejercicio mismo de ese impulso. Ciertos principios de la tonalidad siguen siendo para mí un recurso primordial si tu afán es comunicarte. Un lenguaje ecléctico y enrarecido limita la transmisibilidad de una poética. Para crear una atmósfera emocional que envuelva a un auditorio conviene, pues, recurrir a un acorde o a un arpegio que evoque algo que el público ya ha escuchado: a un arpa, por ejemplo, cuyas sonoridades podrían transportarnos al tiempo de los antiguos griegos... Esta capacidad de evocación 
depende, como dije antes, de la "cita" y de la tradición tonal en toda la historia de la música.

Cuando usted compone, ¿cuáles son los aspectos musicales que quedan a descubierto, pues toman una forma material, y cuáles otros quedan implícitos u ocultos?

Los aspectos emocionales de alguna manera siempre están ocultos. Vivimos en una cultura muy visual, y la música es un arte invisible. En ese sentido, está todo oculto. Todo suena, sí, pero el hecho de escuchar música es un proceso muy misterioso, porque implica oír también lo oculto: el río que va pasando por debajo...

¿Diría usted que eso que se escucha es siempre algo que existe en la naturaleza, es algo que existe en el cuerpo, o más bien, algo que no existe y que se genera en el propio momento en que la forma musical aparece?

Es preciso tomar en cuenta la extrema complejidad del fenómeno musical. En ocasiones, al escuchar música, lo que oigo y me conmueve es quizá sólo un par de armónicos, un par de sonidos, que en efecto me están hablando de la naturaleza: cuando escucho una octava, lo que escucho es un fenómeno físico, una nota en simpatía con su armónico más inmediato. Y esa realidad física de una cuerda al vibrar, evoca las ondas del agua que se mueven igual que el sonido. Al escuchar una secuencia determinada de sonidos y sus resonancias, puedo entrar en contacto con las mismas dinámicas que se observan en un lago o en una catarata...

Pero hay otras veces en que el contacto que provoca la música es con una retórica determinada, que puedo disfrutar en un proceso curioso de abstracción y memoria estética. Si estoy oyendo un himno alemán, con tubas... jolvídate de la naturaleza! Lo que me está transmitiendo esa pieza es elocuente pero 
no tiene que ver con la naturaleza, sino con la cultura, con un contexto social determinado, con la historia.

Habrá ocasiones en que, al escuchar cierta música, lo que oigo y disfruto es una especie de geometría acústica. O quizá cierta pieza evoque una arquitectura, barroca por ejemplo, o gótica: y al escucharla lo que percibo es algo así como una catedral que se está moviendo...

Si es verdad, Maestro, que hay formas que aluden a otras por paralelismo o por contraste, ¿podríamos pensar que esas fórmulas o estructuras musicales están ocultas, y se hacen presentes sólo en la memoria del escucha? Si eso que "suena" en la mente del escucha se combina con lo que objetivamente oye, el efecto de sentido se vuelve algo muy difícil de describir...

Por supuesto. En cuanto a lo oculto y lo manifiesto en una pieza musical habría algo importante que decir: Dado que la música se genera básicamente a partir de citas a sí misma, - - y a otras artes-, una de las maneras de crear sentido es precisamente el enrarecimiento de un código musical implícito. Este enrarecimiento, o "traición" momentánea del principio de composición, conforma precisamente el estilo de un compositor, y refleja, más que ningún otro elemento, su personalidad, tanto como la época en que vive.

Lo mismo pasa con las propias limitaciones del creador. Sus limitaciones, más que su dominio técnico, es lo que va generando un estilo. El modo en que una "cita" queda sugerida, oculta o semioculta, refleja también una tendencia estética. Y quizá a partir de dichos momentos de enrarecimiento o de contención puede realizarse un análisis musical muy interesante. Puede estudiarse el grado de sutileza en el enrarecimiento de fórmulas que utiliza un compositor, y describir así su lenguaje propio.

He dicho antes, cuando hablaba de la posibilidad de componer siguiendo un código Morse, que en la música pueden usar- 
se una gran variedad de parámetros precomposicionales que nunca se manifiestan. Por ejemplo, Alban Berg era un músico serialista que componía a base de números que lo obsesionaban: series como 7, 14 y 23. Y con base en relaciones entre estos números, articulaba formas largas y complejas. El patrón numérico no puede ser descubierto jamás por el oyente, porque están sólo implícitos, ocultos.

El mismo Bach tiene un tema, "El arte de la fuga", cuyo parámetro precomposicional es un motivo formado por su propio nombre: $\mathrm{B}, \mathrm{A}, \mathrm{C}, \mathrm{H}$, iniciales que en alemán se refieren a las notas: si, la, do, si bemol....

Por supuesto que estos parámetros, por más rigurosos que sean, jamás se detectan a la hora de escuchar la obra, aunque de hecho determinen el modo en que están dispuestas sus texturas formales.

Descubrir esas fórmulas precomposicionales haría la euforia de muchos semiólogos y críticos musicales, pero quizá aportaría poco a la descripción de las facultades poéticas de la música.

Sí aportaría, en la medida en que el descubrimiento de esos parámetros permite descubrir después las "desviaciones" y contrastes que forman el estilo peculiar de un compositor.

Yo suelo seguir los principios de la consonancia, pero en un momento dado me aparto de ella. Y eso explica buena parte de mi poética.

La tendencia de muchos jóvenes compositores es la de regresar a principios tonales — que la música popular nunca abandonó- justo por la necesidad de reinsertarse en la tradición. Ello corresponde íntimamente al espíritu de nuestra época, en que el rescate de las raíces se combina con un intenso afán de pertenencia a la comunidad. La cultura "pop", como mencionaba yo antes, responde a una generación más preocupada por "pertenecer" que por crear mundos autónomos. La 
interpretación musical se ha convertido, de hecho, en un acto de expresión comunitaria: lo que se busca es formar parte de "la aldea", la aldea global en este caso, y ya no el aislamiento o diálogo del artista consigo mismo o con otras pocas almas afines.

Como público, nos desagrada hoy en día asistir a la expresión de los sueños individuales de otro. Lo que queremos es entrar en una atmósfera colectiva, en esa especie de hermandad instintiva que la música provoca. Por eso, los temas y estructuras de la música "pop" son en general sencillos y fácilmente comprensibles, incluso en exceso. Y por eso también la música culta, la música de concierto contemporánea, respondiendo al afán de nuestro tiempo, tiene más preocupación por "compartir" una experiencia estética integradora que por abrir horizontes insólitos.

Entrevista y transcripción de Carmen Leñero 
